\title{
Fourteenth International Physiological Congress
}

\begin{abstract}
THE members of the Fourteenth International Physiological Congress assembled at Rome on August 29 in circumstances embarrassing to the lawabiding scientific worker. The approaches to the Campidoglio, where the inaugural session was to take place, proved to be guarded by several cordons of police. After passing a close inspection by a civilian official and, at the doors of the Sala di Giulio Cesare, a final check by two imposing flunkeys, those delegates who had not forgotten their cards of membership were able to hear speeches of welcome by the Governor of Rome, the Minister of Education, and others. An inaugural address by Prof. A. V. Hill should have closed the proceedings, but the Congress was unexpectedly honoured by the appearance of Signor Mussolini, who, in a few graceful phrases, extended to the Congress the welcome of his Government.
\end{abstract}

Prof. Hill, relying on the existence of advance printed copies of his address, earned the gratitude and admiration of many by curtailing severely the academic sections of his speech; bringing incidentally into deservedly greater prominence some timely comments on the "intolerable burden of the literature" under which physiologists, no less than other scientific workers, sweat and groan. "The days are already too short, to read all that appears in print." With bluntness tempered by his usual good humour, he discussed the unnecessary multiplication of papers and pointed to the two major causes of the nuisance - self-advertisement by younger men, whose advancement depends all too often on the weight of paper they have sullied with printer's ink; and, in some countries, profit-making by publishers and owners of scientific journals. All journals should be owned and controlled, he insisted, by scientific societies, and he recommended that the Congress should appoint an international committee forthwith to consider the publication and cataloguing of physiological and biochemical papers. Not only in writing about our work, but also in speaking about it, he further insisted, we too often waste our opportunities and the time of our colleagues at scientific meetings. "There is no excuse for telling busy people in fifteen minutes what they could perfectly well read in five. . . ."

The inaugural meeting finished before lunch, and the remainder of the day was spent in visiting the excavations at Ostia and bathing at the famous Ostia Lido; the serious work of the Congress began on Tuesday, when four parallel sections were held morning and afternoon, each session being composed of six to twelve papers having some central theme in common. A reception offered by His Highness the Governor of Rome at the Palazzo dei Conservatori concluded the activities of the second day. On Wednesday, in addition to the morning and afternoon sessions devoted to the presentation of original papers, Prof. P. Karrer delivered an address to the Congress entitled "Uber Carotinoide und Vitamin A" ; and the evening was the occasion of a banquet given by the organising committee of the Congress at the Hotel Excelsior. At the banquet, consisting mainly of Italian dishes, excellently served, and admirably adapted to the heat of the evening, speeches were made by prominent physiologists from all parts of the world, congratulating the Organising
Committee on the excellence of its arrangements. Thursday was a holiday from all scientific discussion and the Congress journeyed to Tivoli, where it spent a peaceful day in the delightful parks of the Villa Adriana and the Villa D'Este. The Friday afternoon sessions were preceded by a lecture given by Prof. I. P. Pavlov on the more recent work of his school ("La Physiologie de l'activité nerveuse supérieure"). He spoke in German to a large and deeply interested audience.

On Saturday morning a party of members of the Congress was received in audience by the Pope, and, in the afternoon, the concluding session was held in the Royal Academy of the Lincei. After a short speech of welcome by the president of the Congress (Prof. Bottazzi), Profs. Barger and Mansfeld (the former in Italian, to the envy of his colleagues, and the amazement of those who were unaware of his linguistic reserves) conveyed the thanks of the members of the Congress to Prof. Bottazzi and the Italian Organising Committee, and the appreciation of the magnitude of their task. Prof. Pavlov, in the name of the Russian physiologists, then invited the International Physiological Congress to hold its fifteenth meeting in Russia: this invitation was accepted with acclamation. Prof. Frank then proposed that the succeeding Congress, in 1938, should be held in Germany: this also was agreed to. Members of the Congress then visited the picture galleries until it was time to cross the road to the Farnesina Palace, where the Royal Academy of Italy held a reception. In the absence of the president, Senator Marconi, the vice-president received the guests.

On Sunday, a party left for a three days' visit to Naples, and its Marine Biological Station. Excursions were arranged for those who were unable to take part, but wished to remain in Rome another day.

Any detailed description of the subject matter of the four hundred papers communicated to the Congress would be out of place here, and is rendered unnecessary by the publication of the Proceedings in book form by the Organising Committee. Some notion of the activity of physiologists in different fields during the past three years may be obtained from the following summary of the subject matter of each of the thirty-one sessions of the Congress.

2 Sessions each : Circulation, muscle, central nervous system.

$1 \frac{1}{2}$ Sessions each : Carbohydrate metabolism, general chemistry, internal secretions, vitamins, physical chemistry.

1 Session each : Respiration, enzymes, fat metabolism, general metabolism, nerve, blood, digestion, pharmacology, special senses, reproduction, plants and bacteria, cellular physiology.

$\frac{1}{2}$ Session each : Kidney, immunity.

(4 Sessions unclassified. Two half-sessions counted as one session throughout.)

An analysis of the nature of the communications reveals two interesting characteristics: the relative predominance of work of a chemical or physical nature, and the absence of any advance of a notable 
kind in any quarter. Consequently, if we are to mention any particular paper rather than any other, the choice must, of necessity, be made more or less at random, and be influenced as much by our own personal interests, as by the intrinsic merit of the work itself. Indeed, the great difficulty that we found in preparing a review of the scientific proceedings which should be of interest to physiologists in general-we very early abandoned the attempt to make it of interest to workers in other branches of science-has convinced us that the wrong type of paper was presented. An international congress, meeting triennially, besides giving opportunity for personal contacts and private discussion-as was emphasised by Prof. A. V. Hill, in his opening address - should consist mainly, if not entirely, of reviews of the progress made in the last three years. These should be of interest to workers in all branches of physiology. Such a limitation in scope would do much to relieve the present congestion of space-time.

A number of new technical methods have been introduced since the last Congress. In the realm of cellular physiology there is the centrifugemicroscope of Newton Harvey (Princeton), with which he has been able to measure the interfacial tension at the surface of living organisms by observing a cell being pulled into two parts by a known centrifugal force after injecting a drop of oil. Then, in the realm of muscle physiology, there is the method of von Muralt (Heidelberg) for observing the changes in the anisotropic properties of striated muscle during a single twitch by recording the FizeauFoucault bands: further developments of this technique will be awaited with great interest. Lastly, in the realm of cardiology, there is the di-electrograph of Atzler and Lehmann (Dortmund). This is an instrument for recording the output of the heart in human subjects. Two plates are placed, one on the subject's chest and the other on his back; they thus act as a parallel plate condenser and the capacity between them is greater at the end of diastole, when the heart is full of blood, than it is at the end of systole. These changes in capacity are arranged to affect the frequency of an oscillating circuit, and the changes in frequency are recorded as deflections of an oscillograph after suitable detection and amplification. No suggestion is made that the records are quantitative, since much of the blood expelled at each systole is retained in the pulmonary circulation, but the shape of the di-electrograph record. appears to be constant for any given subject under given conditions, and it seems probable that variations in this shape may have diagnostic significance.

The number of communications concerned with muscle physiology reflected the unusual activity which has characterised this field of work during the last few years. E. Lundsgaard (Copenhagen) reported the results of a more exact study of the phosphagen breakdown during activity of muscles poisoned with iodoacetic acid. The strict proportionality between phosphagen breakdown and energy released in a series of isometric twitches $(\Sigma T l)$ earlier reported by him, is confirmed in all cases where the muscle is not too severely fatigued. The energy released never exceeds that which would be derived from the chemical reaction in question. In later stages of fatigue, extra energy is released and this has now been traced by Lundsgaard to the hydrolysis of adenylpyrophosphoric acid.

F. O. Schmidt (St. Louis) reported measurements on the effect of stimulation on the oxygen consump- tion of nerve, leading to the important result that stimuli too small to produce an action current also fail to produce an increase of oxygen consumption. A neat demonstration of this was achieved by choosing stimuli within the range of magnitude over which reversal of the direction of the current affects considerably the magnitude of the action current induced. The extra oxygen consumption was found to be proportional to the action current.

Kato and his co-workers (Tokyo) reported their successful isolation of single nerve fibres from a nerve trunk such as the peroneal or sciatic, and their observation that the effect of stimulation depends upon the size of the fibre. The contractions of muscle fibres innervated by such a fibre obey the all-or-none relation.

The study of 'chronaxie' continues steadily. Lapicque (Paris) read a paper introducing the term 'metachronosis' to indicate the changes in the time relations of excitable tissues in the same way that metamorphosis indicates the changes in their anatomical form. Such metachronosis may be due to toxic agents, such as curare; or it may be physiological, for example, as a result of iterative stimulation of the sympathetic system. Such metachronoses have recently been the chief study of Lapicque's disciples. This paper provoked Rushton to remind us that many workers (notably Keith Lucas) have failed to observe any metachronosis as a result of curarisation, and that one of the most certain ways of changing the apparent time relations of an excitable tissue is to change the size and disposition of the stimulating electrodes.

Representing the physiology of the circulation and respiration, we may instance the communications of Anrep and his co-workers (Cairo), who reported the results of their investigations on the respiratory variations in the heart frequency, using innervated heart-lung and similar preparations. They have come to the conclusion that these variations have both a central and a reflex origin, and their papers were followed by a discussion, which was all the more welcome in comparison with the apathy of the audience on most occasions, and in which Prof. Hering (Cologne) took a prominent part.

Among the more interesting contributions in the field of metabolism were three from R. A. Peters and his school (Oxford) on the nature of the function of vitamin $B$ in nervous tissue. Different parts of the brains of pigeons were minced and incubated in phosphate buffer at $p \mathrm{H} 7 \cdot 4$, and the rate of oxygen consumption measured. In the absence of added substrate, or if the substrate were succinic acid, no significant difference could be observed between the oxygen consumption rate of the tissues of normal and of avitaminous birds. The ability of the tissue to oxidise added glucose was, however, markedly less in the case of avitaminous birds and the difference was even more apparent when lactate was the added substrate. The pathological tissue had in this case only $60-70$ per cent of the respiration rate of the normal. Not all parts of the brain appeared to be affected: the optic lobes gave the most striking results, whilst cerebellar tissue seemed to be unaffected. That the effect is directly related to the vitamin deficiency and is not merely the result of a lowered vitality, was clearly demonstrated by the observation that within 24 hours of the administration of a curative dose of vitamin $B_{1}$ concentrate to birds showing serious polyneuritic symptoms, the tissues in question proved to be normal once more.

No. 3288, VoL. 130] 
Of similar significance is the demonstration that the administration of the concentrate to the minced tissue in vitro abolishes at once the difference between the avitaminous and the normal tissue.

H. E. Himwich and others (New Haven) contributed the results of a careful study of alcohol metabolism in dogs and men. Clear evidence has been obtained of a state of acidosis during the twenty-four hours following the oral administration of ethyl alcohol equivalent in amount to eight "double whiskies'. The bearing of this finding on the measurement of the respiratory quotients of human subjects needs no emphasis.

In the physiology of digestion, mention may be made of the accounts given by Soula and co-workers (Toulouse) on the relation between the blood sugar concentration and the secretion of the digestive juices, and of the studies on the effect of fat on gastric secretion and motility by Lim (Peiping) and Ivy and Zettelman (Chicago).

\section{Co-operation in Electrical Standards}

\begin{abstract}
A FACTOR which has greatly facilitated the rapid development of the electrical industry throughout the world is the close agreement which exists in practically all countries as to the units in terms of which the various electrical quantities are measured. The international adoption of the units of current and voltage, for example, has been a great help to international trade. It is a pity that a similar simplification has not been introduced into the various national units of length, mass and money. Luckily, the agreement in electrical matters is based upon measurements of the highest precision made in the leading laboratories of the world. The close co-operation which exists between the scientific workers and standardising institutions of all nations has made this possible. A brochure recently published from the National Physical Laboratory (H.M. Stationery Office, 2s.), containing Papers 2 and 3 of its "Collected Researches", vol. 24, is an admirable illustration of this co-operation. Part 2 gives the intercomparison of the capacitance (eapacity) and power factor of a mica capacitor (condenser). The tests were made by H. L. Curtis and C. Matilda Sparks of the Bureau of Standards and Dr. L. Hartshorn and N. F. Astbury of the National Physical Laboratory. Part 3 gives an international determination of the electromotive force of the normal Weston cell by P. Vigoureux of the National Physical Laboratory.

A mica condenser was transported on four occasions between the U.S. Bureau of Standards and the National Physical Laboratory. Seven sets of measurements were taken. During the first transportation a change occurred in the capacitance but
\end{abstract}

no subsequent changes were observed. The change in capacitance of a mica condenser with barometric height is normally about $0 \cdot 2$ parts in ten thousand. The differences in the barometric pressure due to the relative altitudes of the two laboratories and ordinary atmospheric variations probably produced a change of less than one part in ten thousand. When due allowance was made, the measurements carried out in the two countries agreed to about the hundredth part of one per cent. This is quite satisfactory seeing that the methods of measure. ment adopted by the two laboratories were quite different.

Mr. Vigoureux's paper gives an account of new determinations of the international units of current and voltage which were made in Berlin in the summer of 1931 by members of the staffs of the National Physical Laboratory, the U.S. Bureau of Standards, Washington, and the PhysikalischTechnische Reichsanstalt, Germany. The measurements were made by weighing the amount of silver deposited when the current flows through a solution of silver nitrate. In the experiments described the same current was passed in succession through the apparatus belonging to the three national repre. sentatives, who each made weighings of the silver deposited. The mean results of a number of experiments agreed to about one five-hundredth part of one per cent. Standard cells used at the various laboratories as standards of voltage were measured in terms of the current so determined, and certain small discrepancies which had been suspected between measurements made in the different countries were accounted for satisfactorily.

\section{Building Research*}

$\mathrm{M}^{\mathrm{A}}$ ANY developments in the work of the Research Station near Watford are described in the Report of the year's work of the Building Research Board recently published, and in spite of necessary economies evidence of useful activities for the improvement of materials and construction are no less apparent than in former years.

The cost of building is influenced by the regulations enforced in connexion with construction, and the modification of these regulations so far as London is concerned has called upon the work of the Station. At the request of the London County Council, a committee has been set up to review the present methods and regulations for the use of reinforced concrete and a considerable part has been taken in

- Department of Scientiflc and Industrial Research. Report of the Building Research Board, with the Report of the Director of Building Research, for the year 1931. Pp. ix +158. (London: H.M. Stationery Office, 1932). 3s. net.

No. 3288, Vol. 130] the work of the Steel Structures Research Committee, resulting in revised regulations by the Council on the subject of steel-framed buildings which should appreciably assist the steel industry and help to reduce building costs.

Tests on building materials are naturally a large item in the list of the researches undertaken by the Station and the increasing number of requests for such tests from outside has made some definite policy on this matter imperative. It has been decided to enlist the services of approved firms of testing engineers and institutions in carrying out this work under the supervision of the Station rather than incur large capital outlay, and this effort to reduce overlapping and utilise existing agencies is to be commended. The tests thus made will be to the approval of the Station, which will issue certificates upon them. 